\title{
Sources of variation in composition of milk fat
}

\author{
O. SYRSTAD, N. STANDAL and $\theta$. KARIJORD \\ Depurtment of Animal Genetics and Breeding, Agricultural University of Norway \\ 1432 is s-NLH, Norway
}

Fatty acid composition of milk fat in nearly 7000 samples from about 3500 cows sired by 114 A.I. bulls was determined by gas liquid chromatography. The findings may be summarized as follows :

a) Stage of lactation was found to have a significant influence on the proportion of all fatty acids. Most short-chain acids showed a maximum and most long-chain acids a minimum in mid-lactation.

b) Repeatability estimates for proportion of various fatty acids ranged from zero to 0.37 , and heritability estimates from 0.05 to 0.26 .

c) The genetic correlation between fat percentage and the proportion of various fatty acids was consistently positive for the short-chain acids and negative for the $\mathrm{C} 18$ acids.

\section{Frozen embryos as genetic resources. Theoretical considerations, cost estimations and practical experience}

\author{
G. BREM, F. GRAF and H. KRÄUSLICH \\ Lehrstuhl für Tierzucht der Ludwig-Maximilians-Universität München \\ VeterinärstraBe 13, 8000 München 22
}

\begin{abstract}
Preservation of cattle breeds by frozen/thawed embryos allows conservation of extrachromosomal genetic material, immediate reestablishment of purebred populations of extinct breeds and establishing of control population for direct measurement of genetic changes. Costs depend on the rates of success. About DM 100000 might be sufficient for a embryo-bank which is sufficient to reestablish a breed. Practical experiences in establishing a embryo-bank of the breed Murnau-Werdenfelser (17 frozen in 2 years) show that it becomes very difficult if population size is already low.
\end{abstract}

\section{Effects of different deep freezing and thawing procedures on the developmental capacity of bovine embryos}

\author{
H. NIEMANN, B. SACHER, E. SCHILLING and D. SMIDT \\ Institut für Tierzucht und Tierverhalten (FAL) Mariensee \\ D-3057 Neustadt 1
}

This report is about some problems of deep-freezing cow-embryos. The older blastocysts (day 8) had better survival rates than the younger morula stages (day 6). Only insufficient survival rates were achieved with a slow freezing and thawing procedure $(42.1$ p. 100 with DMSO, 21.3 p. 100 with Glycerol). 58.7 p. 100 of the embryos survived with the fast method (transfer into liquid nitrogen at $-35^{\circ} \mathrm{C}$, thawing in warm water) and Glycerol 